\title{
Nondestructive determination of drying deformations in cement paste by means of ESEM and digital image analysis
}

\author{
Dragana Jankovic* \\ Gradacacka 37, 71000 Sarajevo, Bosnia-Herzegovina \\ *Delft University of Technology, Civil Engineering Dep., Microlab, Delft, Netherlands
}

\begin{abstract}
Novel modifications of an environmental scanning electron microscope (ESEM) were made in order to measure the local deformations in drying cement paste. These nondestructively determined moisture-induced plane strains, obtained in 1 $\mathrm{mm}$ thick cement paste samples, are orthotropic. They vary with variations of relative humidity between $70 \%-80 \%$ and $40 \%-50 \%$, being the highest at $20 \% \mathrm{RH}$. Both drying shrinkage and expansion of cement paste microstructure occur in early-age and mature samples. Microcracking due to moisture gradient could not be avoided, although very thin samples were examined with gradual reduction of relative humidity in drying steps of $10 \%$. The coefficient of deformation of cement paste is directly proportional to shrinkage/expansion. It depends on variations of relative humidity during drying in ESEM and the sample age.
\end{abstract}

Keywords: drying, cement paste microstructure, ESEM, shrinkage, expansion, microcracking, coefficient of deformations

\section{INTRODUCTION}

Moisture transport and differential drying, at an early age, induce strains in concrete, particularly in cement paste microstructure. 'Moisture-induced' shrinkage strains can be treated in a manner similar to external (mechanicallyinduced) strains. They appear due to moisture gradients, which 'behave' similarly to an external load [1]. The relationship between differential moisture-induced shrinkage strains $\Delta \varepsilon_{s h}$, and moisture gradient $\left.(\Delta h)\right)$ is assumed linear as follows:

$$
\Delta \varepsilon_{s h}=\alpha_{s h} \Delta h
$$

where $\alpha_{s h}$ is a shrinkage coefficient [2], typically determined from the overall macro-scale shrinkage in the drying range from $100 \%$ to $40 \%$ RH [1]. The drying shrinkage strains may exceed the typically low tensile strength of the cement paste matrix and induce microcracking. If microcracking and deformations increase in the later phases of a structure, they may cause its severe deterioration. It is therefore important to better understand the behaviour of cement-based microstructure at a very young age in order to prevent problems at later ages. To experimentally determine the early age 'real' shrinkage and shrinkage coefficient of multi-phase cementitious materials, it is necessary to directly investigate not only overall shrinkage [3-6], but local drying shrinkage of a thin sample at the scale of microstructure (micro-scale). By testing of a thin sample with slow lowering of relative humidity (RH), the 'apparent' shrinkage (moisture gradient and cracking) is minimized [7,8]. Due to earlier limitations in imaging technology, difficulties in handling a thin sample, and time consuming tests, direct shrinkage tests at the micro-level were rarely performed [9-11] and no data on determination of the micro-scale shrinkage coefficient are found.

The aim of the current research is to determine shrinkage deformations and the coefficient of deformation of neat cement paste due to drying at the micro-scale by means of nondestructive testing in an Environmental Scanning Electron Microscope (ESEM). As a case study, the effect of sample age is considered. The drying of neat cement paste is performed with ESEM type XL30 [12]. ESEM allows observations of wet samples and 'in situ' microstructure changes due to drying, invoked by variations of relative humidity in ESEM chamber. The nondestructive examination of cement paste requires a special (thin) sample preparation as well as adjustments and improvements of ESEM cooling stage. There is always an issue of size effect when it comes to tests on thin samples, but the standard specimen size for drying shrinkage tests is still not established. Due to the lack of feasibility of manual measuring small displacements and strains $(0.01 \%$ or lower), the resulting drying shrinkage displacements and strains are determined by means of a digital image correlation technique. The coefficient of shrinkage deformation is computed in the drying range $100 \%-20 \% \mathrm{RH}$.

Optical Micro- and Nanometrology in Microsystems Technology II

edited by Christophe Gorecki, Anand K. Asundi, Wolfgang Osten

Proc. of SPIE Vol. 6995, 69950G, (2008) - 0277-786X/08/\$18 - doi: 10.1117/12.780731

Proc. of SPIE Vol. 6995 69950G-1 
A method of regression is applied based on the strain results from the Vic-2D correlation analysis of drying deformations. The coefficient has been used as input in the numerical analysis (Lattice Fracture Model) for simulation of the cracking pattern induced by drying [13].

\section{EXPERIMENTS}

\subsection{Specimen preparations}

Portland cement paste (type I, $32.5 \mathrm{R}$ ) with water/cement mass ratio (w/c) 0.5 , were initially cast as thin and small-sized samples $(10 \times 10 \times 2 \mathrm{~mm})$ in specially designed moulds [14]. The casting of thin and small-sized samples is performed to avoid: (1) the apparent shrinkage mechanisms, and (2) eventual damage and consequential microcracking due to cutting the thin sample from the larger sample. The samples are wet cured in lime-saturated water $\left(\right.$ at $95 \% \mathrm{RH}$ and $\left.20^{\circ} \mathrm{C}\right)$ prior to testing. A specially designed cylindrical tool (Fig. 1a) is used for manual sample grinding and polishing to the thickness of $1 \mathrm{~mm}$ (Fig. 1b). Since the sharp images in ESEM can be acquired only from a freshly exposed and very well polished surface, the grinding and polishing is performed on the day of tests in wet conditions. Any surface impregnation (applied for monitoring of eventual cracks) or coating is avoided, as it would disable water evaporation from the specimen surface.

\subsection{New ESEM cooling stage}

The cooling stage (internal ESEM unit) provides a wet environment in the ESEM chamber via liquid circulation and cooling/heating of the sample on the ESEM stage. As a standard part of ESEM, a Peltier cooling stage is used for drying of small samples $(5 \times 5 \mathrm{~mm})$. Due to the sample size used in these new tests $(10 \times 10 \times 1 \mathrm{~mm})$, the usual Peltier cooling stage could not be used so a new stage was built. The new cooling stage consists of a metal cover and two plastic pipes, which are fixed to the stage box ('house'), Fig. 2.

To better control relative humidity, an existing PVC cooling house (Fig. 3a) with a wire for liquid heating and amplifier for signal amplifying during surface temperature measurements was improved (Fig. 3b). The improvement is made in the inbuilt thermocouple sensors/transistors instead of heating wire as well as integrated circuits inside the polyvinyl box, which were used to measure temperature at the bottom of sample (on the brass plate). Conjunction compensation (CJC), which takes over a role of amplifier, is placed on the inner metal cover (Fig. 2a). Another improvement was placing a conductive paste as a heat conductor between brass plate and transistor (inside the cooling box). A new inbuilt thermocouple (or thermo-electric couple) is based on the Seeback effect, which is opposite to the Peltier effect. Both effects operate on the principle of forming an electric circuit in two wires of different metals welded together. Besides a heating element, the cooling box has two sensors for the control of the sample temperature. The temperature of a sample is measured at the bottom (T1) and on the top (T2). One sensor is used for the measurement of the overall stagetemperature at the bottom of the sample (T1) and the other is placed close to the specimen surface (T2). The surface temperature, T2 is measured by placing a wire, which is 'glued' to the specimen surface with a conductive paste (Fig. $3 b)$. Temperature in the external part of cooling unit is controlled in the reservoir and in the PI controller, which is connected to ESEM. For these particular tests, the temperature in the reservoir was fixed to $10^{\circ} \mathrm{C}$, to allow larger scale pressure changes.

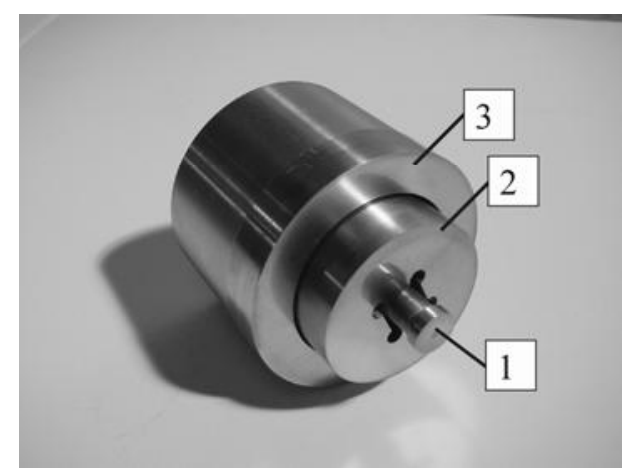

(a)

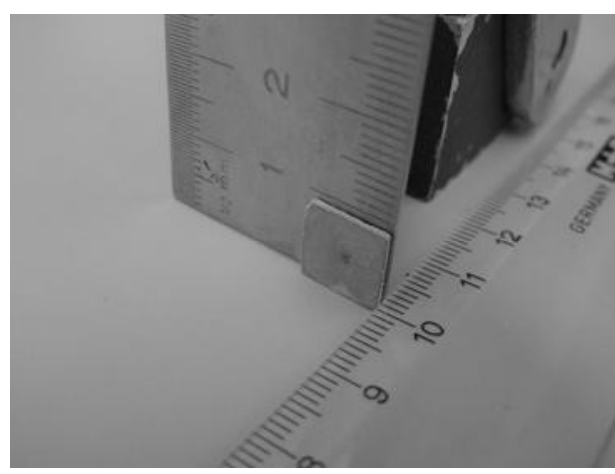

(b)

Fig. 1. (a) Assembled cylinder for grinding and polishing of samples (10 x $10 \times 2 \mathrm{~mm})$ : (1) circular plate, (2) middle cylinder, (3) external cylinder. (b) Ground and polished sample $(10 \times 10 \times 1 \mathrm{~mm})$, ready for testing. 


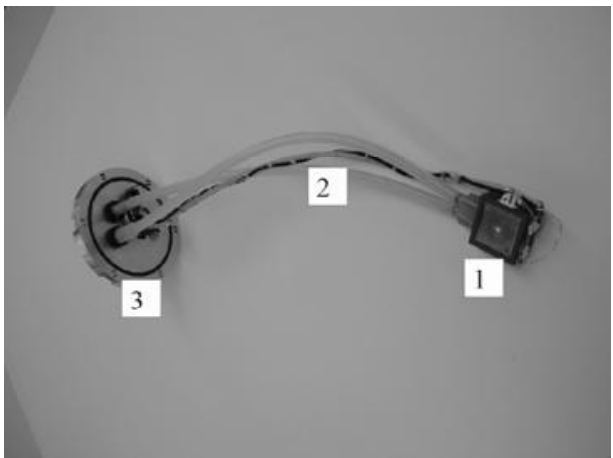

(a)

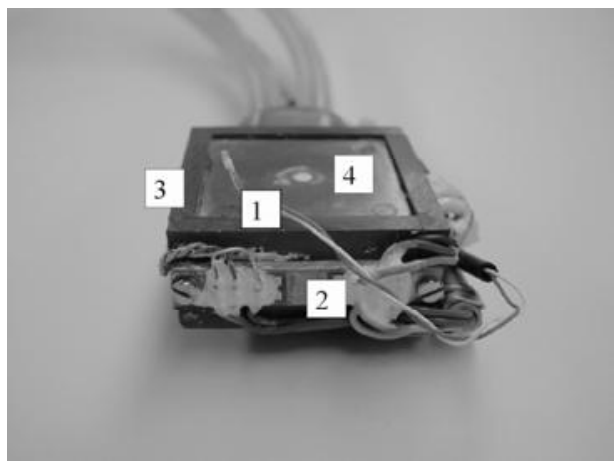

(b)

Fig. 2. Cooling stage placed inside ESEM chamber. (a) Three main parts of cooling device are: (1) cooling box/house, (2) inner pipes and (3) steel cover of ESEM with CJC unit. (b) Cooling box with thermocouple/transistors (1) and inbuilt integrated circuit (2) inside the polyvinyl box (3) with brass plate on top (4) for sample placing.

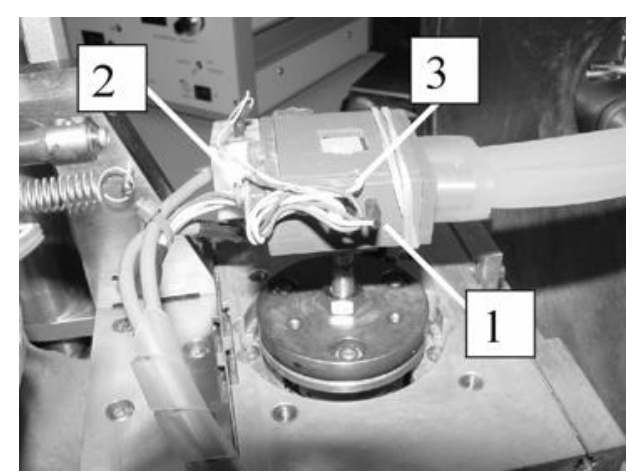

(a)

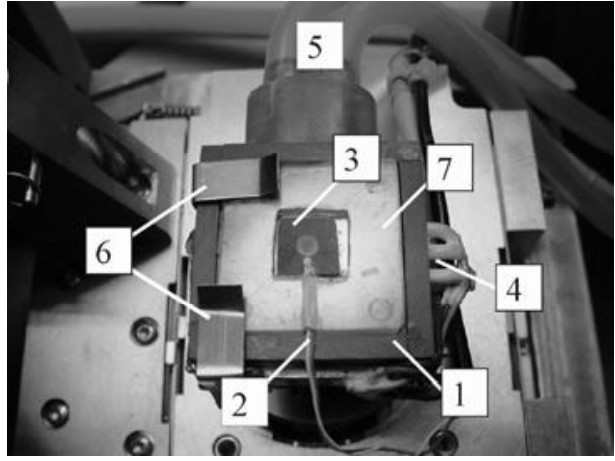

(b)

Fig. 3. (a) First PVC cooling house (1), with a wire for heating (2), and exposed amplifier (3) for amplifying the signal during temperature measurements. (b) Improved cooling house (1), with inbuilt thermocouple sensors and conductive paste (2), for temperature measurements on the surface of a sample (3), and integrated circuits inside the polyvinyl box (4), (5) pipes for liquid circulation, (6) metal clamps, (7) plastic frame around sample.

\subsection{Drying procedure in ESEM}

Relative humidity in ESEM chamber is created by controlling a pressure and a temperature. The drying is induced by lowering the pressure and keeping the constant temperature. The initial (prior to drying) conditions in ESEM chamber were $100 \% \mathrm{RH}$, which was induced by 9.1 torr and app. $10^{\circ} \mathrm{C}$. The drying, induced by a stepwise reduction of RH by $10 \%$, from $100 \%$ to $90 \%, 80 \%, 70 \%, \ldots$, and $20 \%$, is performed every time the equilibrium is reached i.e. when oscillations in pressure and temperature diminish. The minimum pressure is 1.8 torr (at $20 \% \mathrm{RH}$ ). The drying below $20 \%$ RH often induced blurry images due to very low pressure. Equilibrium time depended on the sample age and curing conditions. It varied between 15-20 min. Only when the specimen is equilibrated with the air, becomes the RH of a specimen equivalent to the RH of the surrounding air. Otherwise, the RH of a specimen is equivalent to the RH of the air inside the specimen i.e. pore humidity. Since the specimen is very thin $(1 \mathrm{~mm}$, Fig. 1b), the drying of a 3-D cement paste is observed as a 2-D problem. All drying observations are focused on the surface of the sample. Although the intension was to measure unrestrained shrinkage deformations, the weak 'fixation' of a sample to the brass plate of cooling stage could not be avoided (Fig. 3b). A thin layer of a conductive paste was used to fix the sample and prevent it from moving on the plate, and to control the temperature more accurately.

\subsection{ESEM images}

ESEM digital images are acquired only at one middle spot, due to the insufficient accuracy of ESEM stage movement across the sample. The images are acquired at each drying interval from $100 \%$ to $20 \% \mathrm{RH}$. Digital images in ESEM are produced from signals (secondary low energy electrons, SE) that are emitted from the surface of the sample when it has been 'bombarded' by electrons from the electron gun (tungsten). To detect these electrons, a special GSE (gaseous 
secondary electron) detector for non-vacuum environment was used. It uses gas ionization around the sample to detect and amplify the secondary electron signal.

In order to gain reasonable results from the image analysis, the surface of the specimen must be flat, and any out-ofplane warping must be avoided. All digital images were acquired at the same magnification (scale bar $=50 \mu \mathrm{m}$ ), in order to properly correlate all relevant images. To avoid possible errors during iterations, the digital images were acquired with high resolution (1424 x 968). This creates non-square pixels with pixel size ratio $(\mathrm{y} / \mathrm{x}=0.907)$. The pixel shape is taken into account as aspect ratio during strain calculation. The size of a pixel in $(\mu \mathrm{m})$ varies with magnification and direction ( $\mathrm{x}$ or $\mathrm{y}$ ). For the magnification where the scale bar $=$ of $50 \mu \mathrm{m}$, the $\mathrm{x}$-size of the pixel is $0.2 \mu \mathrm{m}$ and $\mathrm{y}$-size is $0.18 \mu \mathrm{m}$. For the magnification where the scale bar $=$ of $5 \mu \mathrm{m}$, the $\mathrm{x}$-size of the pixel is $0.02 \mu \mathrm{m}$, and y-size is $0.018 \mu \mathrm{m}$. That means that field of view observed under ESEM is approximately $280 \times 180 \mu \mathrm{m}$ when the scale bar $=50 \mu \mathrm{m}$ or approximately $28 \times 18 \mu \mathrm{m}$ when the scale bar $=5 \mu \mathrm{m}$. To minimize noise, which increases remarkably as soon as the pressure (relative humidity) in the ESEM chamber is lowered, images are taken when the temperature and the pressure equilibrium is established without any fluctuations.

\section{DIGITAL IMAGE ANALYSIS}

Computation of displacements and strains is performed with the commercial code Vic-2D. The code is based on mapping and correlation technique. The principle of the 2-D mapping technique is searching for the similar pixel-based intensity pattern in the 'reference' image (taken initially at $100 \% \mathrm{RH}$ ) and the 'deformed' image (taken at all other reduced RH). Since the intensity pattern is a 2-D projection of the object onto plane [15], it is used for the basis of calculation of displacements and strains. Namely, it is assumed that the mapping of local subsets is equivalent to the mapping that applies to the deformation of the object surface, which reflected the intensity pattern [16].

All deformed images in Vic-2D are correlated to the reference image via chosen subsets, so-called Area-Of-Interest (AOI), Fig. 4a. The size of the subsets was (1334 x 878) pixels, excluding image edges of ( $90 \times$ x 90) pixels. The AOI is chosen where no cracks occur; otherwise the calculation of displacements is not valid. In the AOI, the tracking of translation and rotation of imaginary point $\mathrm{P}(\mathrm{x}, \mathrm{y})$ related to point $\mathrm{Q}(\mathrm{x}+\mathrm{dx}, \mathrm{y}+\mathrm{dy})$, is performed (Fig. $4 \mathrm{~b})$. It is assumed that in-plane arbitrary line segment PQ $(\mathrm{dx}, \mathrm{dy})$ remains infinitesimally small $\mathrm{P}^{*} \mathrm{Q}^{*}\left(\mathrm{dx}^{*}, \mathrm{dy}^{*}\right)$ after the deformation. The adequate choice of a subset- and the step-size is chosen as the subset-size 100 and the step-size 15 . Since both translation and rotation are assumed in the samples, the derivatives of $u$ and $v$ displacements (Fig. $4 \mathrm{~b}$ ) become unknowns. The unknowns are initially assumed and then calculated for the center point of the subset during comparing of the intensity values from undeformed subset to all deformed subsets. The error is calculated by a cross correlation function with a more accurate Quintic Bi-spline interpolation (surface fit) [17].

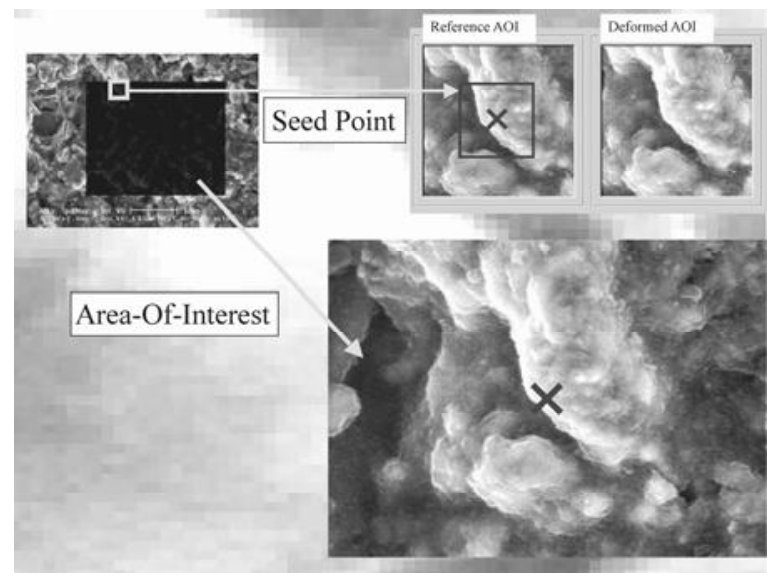

(a)

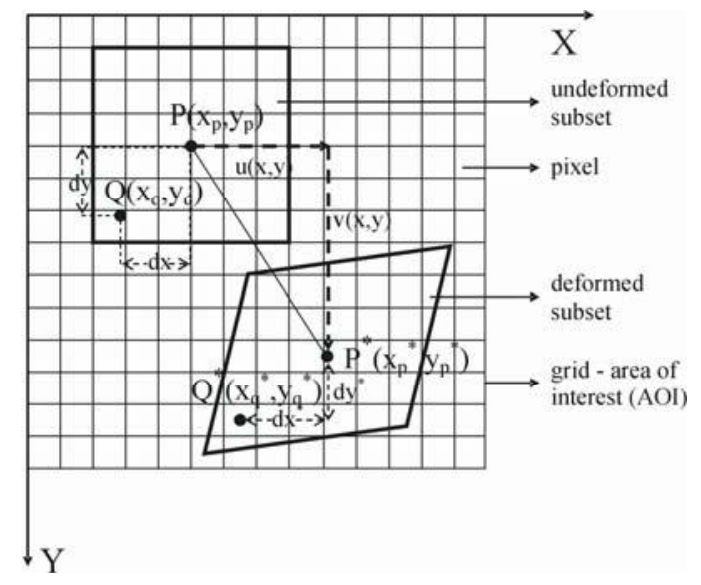

(b)

Fig. 4. (a) Arbitrarily chosen Area-Of-Interest (AOI) or a subset, and a seed point in the digital image analysis with Vic-2D programming code. The seed point, the point in the reference image where the correlation starts, is chosen at the spots where some recognizable features exist. (b) Deformation of a subset in a sampling grid, after [15]. 
Introduction of higher accuracy is necessary, especially when it comes to shrinkage deformations in the complex microstructure of cement paste. The 2-D 'in-situ' displacements $(\mathrm{u}, \mathrm{v})$ and Lagrangian strains $\left(\varepsilon_{\mathrm{xx}}, \varepsilon_{\mathrm{yy}}, \varepsilon_{\mathrm{xy}}\right)$ are computed as well as principal strains. The components of strain are two normal strains $\left(\varepsilon_{\mathrm{xx}}\right.$ and $\left.\varepsilon_{\mathrm{yy}}\right)$ and a shear strain $\left(\varepsilon_{\mathrm{xy}}\right)$. The average value of each strain component is given in the diagrams (Fig. 5). The principal strains do not differ much from the strain components and they are not showed.

\section{DISCUSSION OF RESULTS: EFFECT OF AGING}

The ESEM drying test results of 4, 5, 32 and 52 days old samples are presented. Their age at the time of test is equivalent to their curing age. To determine real shrinkage, reduction drying steps $10 \%$ and $20 \% \mathrm{RH}$ are chosen. Only the drying shrinkage results with the drying step $10 \% \mathrm{RH}$ are presented here.

Strain-RH diagrams. Although the linear relation between strains and RH (Eq. 1) was expected, the diagrams in Fig. 5 show the opposite. The $10 \% \mathrm{RH}$ drying step was supposed to induce more gradual drying in ESEM but the sharp oscillations (change of a slope) unexpectedly appeared around $70 \% \mathrm{RH}, 40 \%-50 \% \mathrm{RH}$ and below $20 \% \mathrm{RH}$ in all samples. The oscillations could be related to the technical properties (sensitivity) of microscope itself, since such drastic oscillations in strains did not occur during drying with a higher step $(20 \% \mathrm{RH})$. The oscillations around $70 \%-80 \% \mathrm{RH}$ were especially high in young (4-day) samples (Fig. 5a), but reduced with aging (Fig. 5b-d). This could be also attributed to a higher water loss at high RH [18], especially in cement paste with w/c 0.5. Usually, water loss at high RH does not induce extreme strains in mature samples. In the case of 4-day sample, it induced high (0.008) but reversible shrinkage/expansion probably due to the soft and less stable microstructure at an early age.

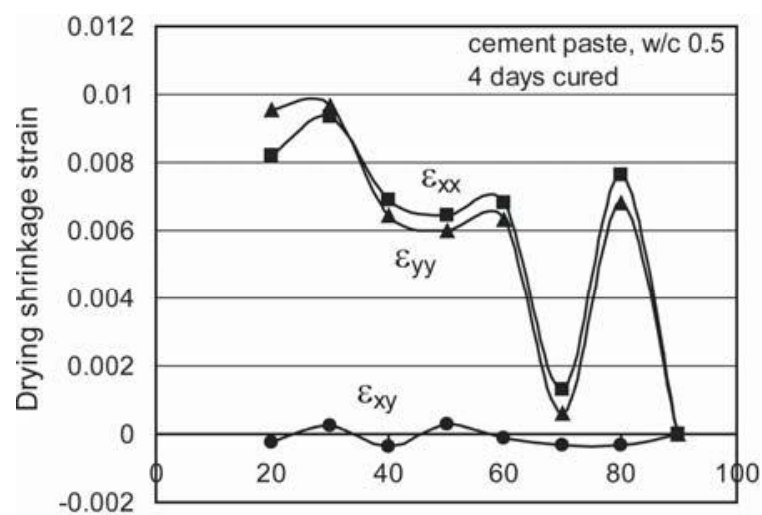

Relative humidity $\mathrm{RH}$ (\%)

(a)

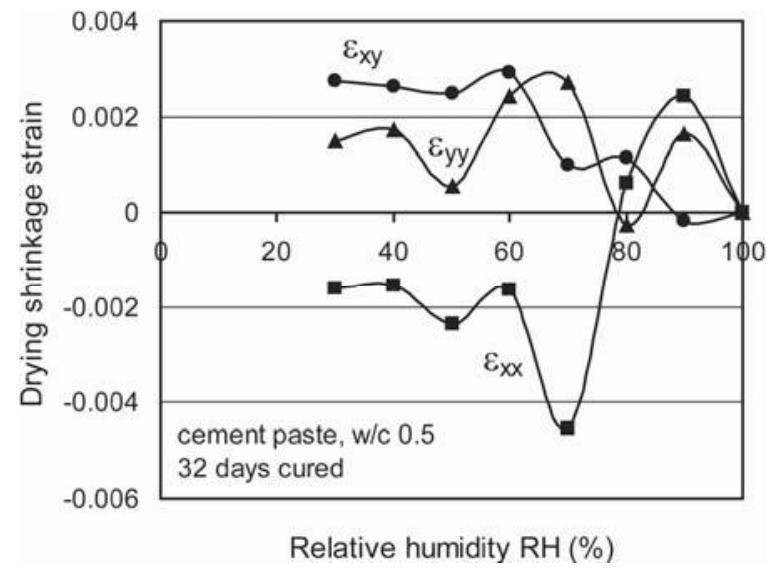

(c)

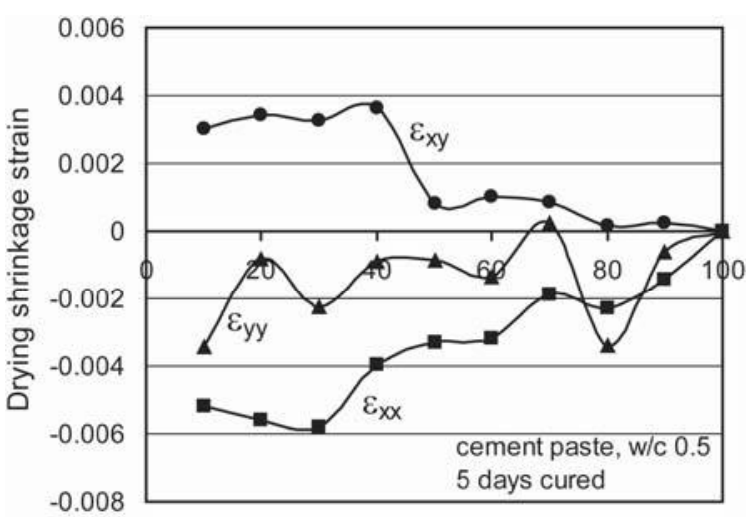

Relative humidity $\mathrm{RH}$ (\%)

(b)

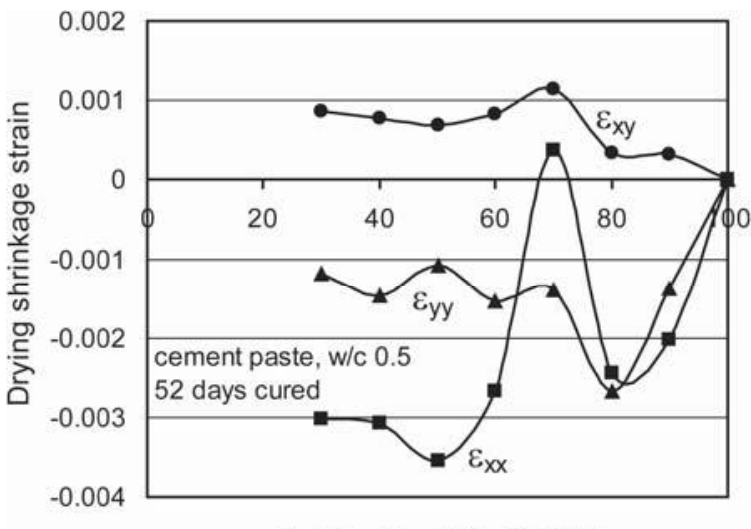

Relative humidity $\mathrm{RH}$ (\%)

(d)

Fig. 5. Average drying shrinkage strains as a function of RH based on the image analysis (scale bar $=50 \mu \mathrm{m}$ ) of the AOI (1334 x 878 pixels), in wet cured samples (CEM I 32.5, w/c 0.5) at (a) 4, (b) 5, (c) 32 and (d) 52 days of age. 
Unlike drying tests at macro-scale, which showed more or less uniform drying deformations [3-6], micro-scale tests showed the orthotropical deformations regardless of the sample age. This is related to the heterogeneity of a cement paste microstructure. The test results (Fig. 5), show that both shrinkage strains $\left(\varepsilon_{\mathrm{xx}}, \varepsilon_{\mathrm{yy}}\right)$ and expansion (typically shear strain, $\varepsilon_{\mathrm{xy}}$ ) occur during drying. The observation of expansion and shrinkage approximately match with the drying test results on thin samples by Roper [19], and Neubauer and Jennings [18]. The expansion of a microstructure could be expected at an early age. In the very young samples (for example 4 days of age, Fig. 5a), swelling develops in almost all directions, while already at age 5 days (Fig. 5b) and after 28 days of age (Fig. 5c-d) expansion is overcome by shrinkage. It is noticed that extremely high deformations appeared almost simultaneously as expansion strain (app. 0.025) and shrinkage strain app. (-0.025) in samples over 28-day of age (32- and 52-day samples, Fig. 5c-d). The appearance of the high deformations is always followed by microcracking.

The expansion at young age is primarily related to the wet curing conditions but also sample age and water/cement ratio. At the young age, hydration is still very active and in thin, wet cured samples, rapid growing of hydration products appears as swelling (expansion), which continues even during drying. That could explain the increase in weight, which was measured in all samples during curing. The weight was measured at the time the samples were demoulded (on the

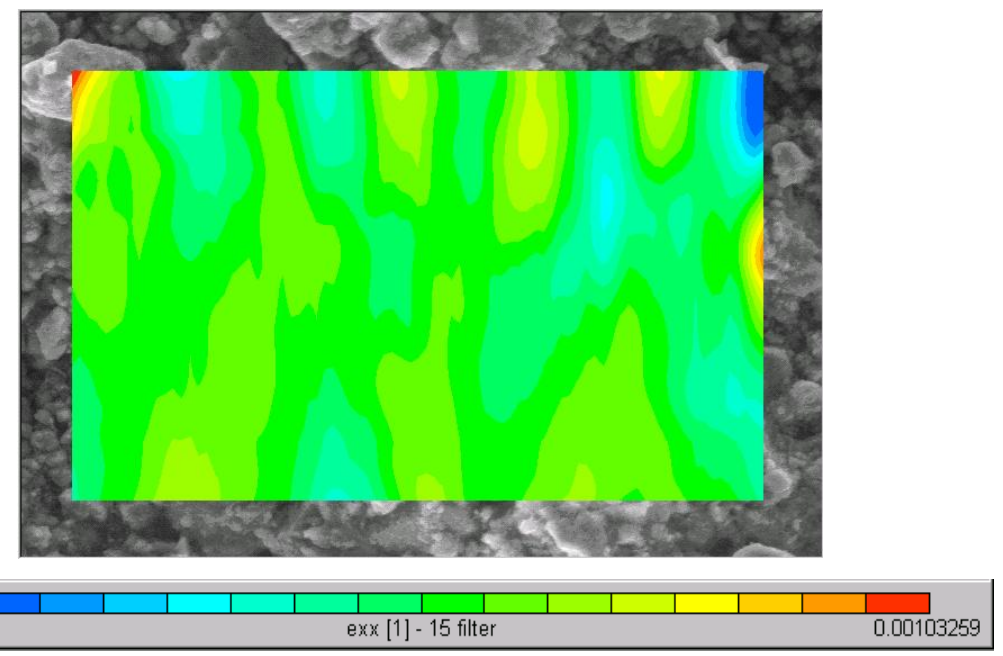

(a)

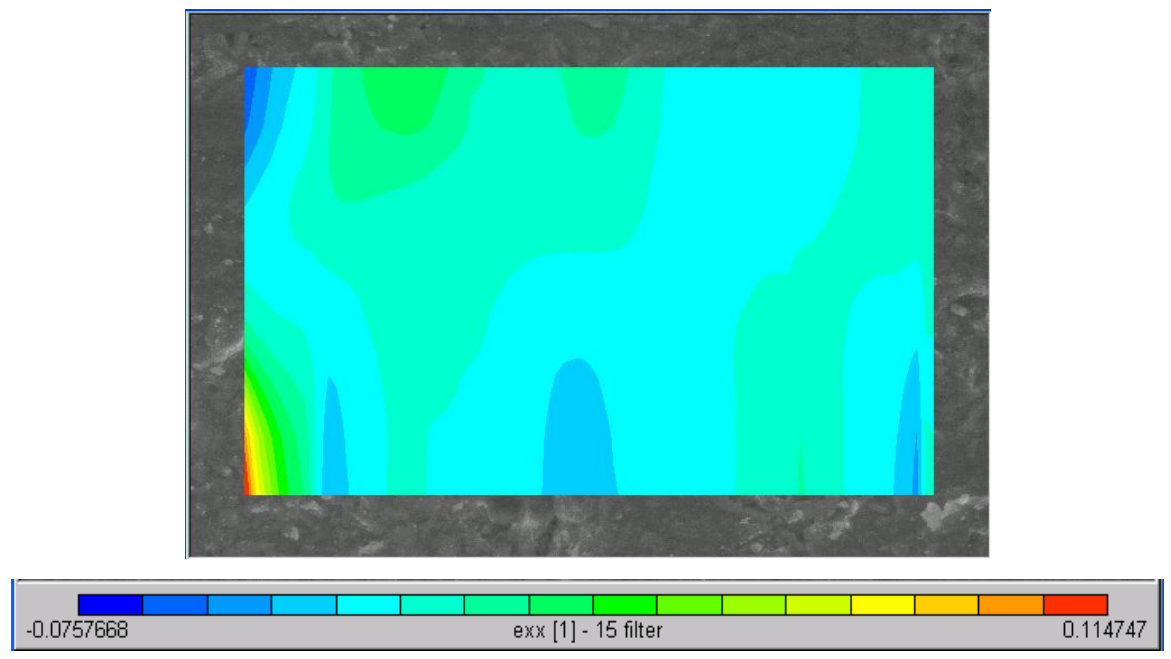

(b)

Fig. 6. Strain distribution $\left(\varepsilon_{\mathrm{xx}}\right)$ in a chosen Area-Of-Interest (AOI), size 1334 x 878 pixels, at 20\% RH at: (a) 5 days and (b) 52 days. Total area observed under the ESEM beam (scale bar $=50 \mu \mathrm{m}$ ) is $1424 \times 968$ pixels or $280 \times 180 \mu \mathrm{m}$. 
first day of curing) and on the day of test (on the last day of curing). The increase was higher in very young samples (app. 3.5\%) compared to 3\% which was measured in older samples. For example, in dry cured samples (not presented here), practically no swelling appeared. Hence, the weight loss was noticed even at young age. While in 2-4 days wet cured samples linear strains appear as mostly swelling strains, shear strain practically does not exist. Already in the 5-day sample, shear strain appears as swelling (expansion) and linear strains as shrinkage, which could be attributed to the increase of stiffness after 5 days. With aging, the shear (swelling) strain remains but it is gradually reduced. It is also observed that all deformations, expansion and shrinkage, decrease with aging (Fig. 5). This probably has to do with the development of the main hydration product C-S-H (calcium silicate hydrates), which is, after 28 days, clearly divided into two phases: low-density (LD) C-S-H, and high-density (HD) C-S-H [20]. Since HD C-S-H generally deforms less, the deformations reduce even more with aging such that total deformations are reduced. It is known [21] that in liquids, surface tension and surface energy are numerically equal, while in solids, they have at least the same order of magnitude. During aging surface area decreases. This indicates that the equilibrium in moisture content at constant humidity is dependent upon aging.

In older samples, the shrinkage response of the two-phased C-S-H to the external conditions appears as lowering of the potential surface energy/area (surface energy is effective at higher humidity 100\%-40\%), liberating a certain amount of energy and increasing atomic ordering [22]. In that way, C-S-H structure stabilizes and is less prone to environmental influences, such as drying. Thus it shrinks less. The capillary and gel pores where water/vapour flows are reduced and the deformations of low-density phase, LD C-S-H are reduced; the set of pores in older cement paste behaves similarly as cement pastes with low $\mathrm{w} / \mathrm{c}$ ratio.

Distribution of strains. The distribution of strains (Fig. 6), calculated in the center of every pixel, results also from the Vic-2D image analysis. The distributions in the whole AOI are obtained for displacements $\mathrm{u}$ and $\mathrm{v}$, as well as for every strain component $\left(\varepsilon_{\mathrm{xx}}, \varepsilon_{\mathrm{yy}}, \varepsilon_{\mathrm{xy}}\right.$ ) at each drying step (from $90 \% \mathrm{RH}$ to $20 \% \mathrm{RH}$ ). The max and min strains are presented on the scale below the image (Fig. 6). The examples of strain distribution after drying to $20 \%$ RH (Fig. 6) show that the highest shrinkage/swelling is concentrated only locally, regardless of age, but with the variations in values. During drying, the local areas of high or low strain displace. Mostly the areas of low deformations are separated by the areas of high deformations. For example, in AOI of 5-day sample at 20\% RH (Fig. 6a), the expansion in x-x direction dominates, while separated with smaller areas that shrink. The AOI of 52-day sample at $20 \%$ RH (Fig. 6b) shows complete shrinkage in $\mathrm{x}-\mathrm{x}$ direction, accept tiny area (at the lower left corner), which swells. The reason for local deformations of cement paste is the heterogeneity of microstructure and the developing phase of hydration products at the moment of testing, namely deformable LD C-S-H and non-deformable hydration products such HD C-S-H, CH (calcium hydrate), as well as ettringite.

Microcracking. Although cracking is considered an apparent shrinkage mechanism, which should be avoided by drying of thin specimens at low drying steps, scattered and discontinues microcracking developed in most of the thin samples. Microcracking emerged regardless of the drying step $(10 \%$ or $20 \% \mathrm{RH})$ or a sample age. The possibility of microcrack appearance increased with aging and with increasing size of drying steps $(20 \% \mathrm{RH})$. In the very young cement paste $(2-4$ days old), dried with drying step $10 \% \mathrm{RH}$, microcracking was rarely noticed. This is probably related to the colloidal and elastic cement-based microstructure at an early age. It is interesting that although large change of slope is present in 4day sample (Fig. 5a), no cracking was noticed. As the microstructure gets more rigid at 5-52 days of age, microcracking occurred almost regularly, probably due to sample aging (Figs. 7, 8). In the 5-day sample (Fig. 7a), which was dried to $10 \% \mathrm{RH}$, and short rewetted to $25 \% \mathrm{RH}$ for the image improvement, the $3 \mu \mathrm{m}$ thick microcrack was noticed. When the sample was rewetted to $92 \% \mathrm{RH}$ for $20 \mathrm{~min}$, the microcrack was only partially healed (Fig. 7b). Due to the young sample age, the microcrack would possibly fully close if exposed to rewetting in a longer period. It remains unknown if the microcrack in 30-day sample would also heal. According to Freyssinet [23], there are experiments which categorically proved that fractures would heal themselves if the distance between the fractured surfaces was not excessive and if sufficient moisture was present.

It was not possible to confirm exact RH at which microcracking occurred, but it could be speculated that microcracking occurred below 40\% RH. Microcracking is influenced by similar mechanisms as assumed for the shrinkage phenomenon: meniscus rupture in capillary pores, surface energy decrease of C-S-H, but also by the aging of the C-S-H and chemical modifications. Most shrinkage mechanisms are related to changes of surface area and surface free energy. Due to drying and heating, the internal surface energy is reduced, while creating a more stable structure and liberating certain amount of energy [24]. With drying, internal surface in older samples (even 5 days old, Fig. 5b), reduces substantially compared to the young 4-day samples (Fig. 5a). 


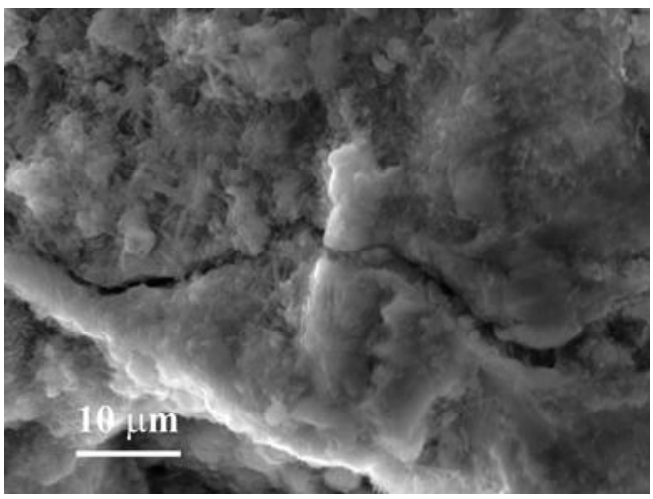

(a)

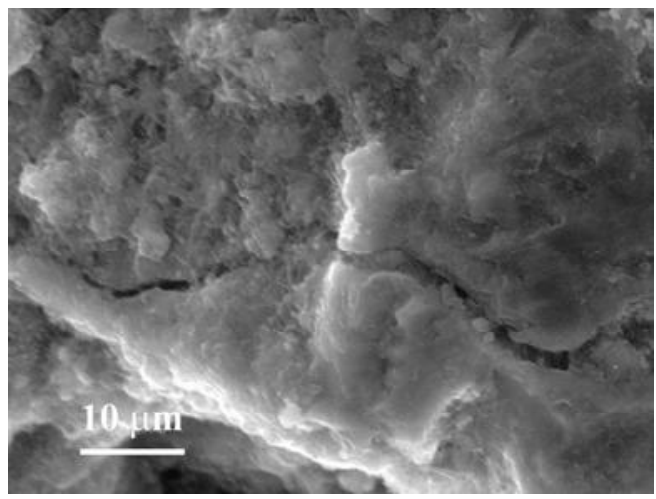

(b)

Fig. 7. Microcrack in 5 days wet cured sample (CEM I 32.5, w/c 0.5). (a) Image taken after drying to $10 \%$ and short rewetting to $25 \% \mathrm{RH}$ for the image improvement. (b) Image taken after 20 min of rewetting to $92 \% \mathrm{RH}$. Partial closure of the crack is visible around the middle part of the crack.

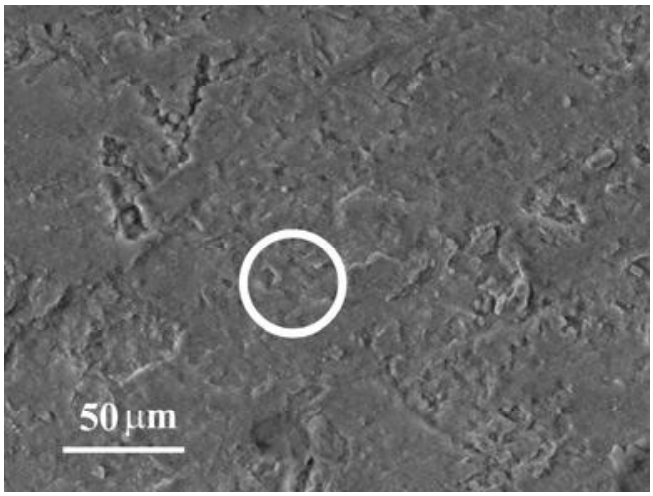

(a)

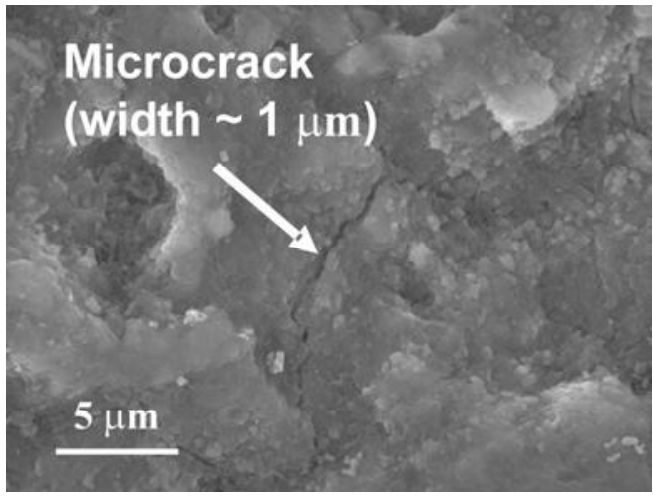

(b)

Fig. 8. Microstructure of 52 days wet cured cement paste (CEM I $32.5 \mathrm{R}$, w/c 0.5 ) after drying to $20 \%$ RH (a) at a scale bar size $=50 \mu \mathrm{m}$ and (b) enlarged circled area when the scale bar size $=5 \mu \mathrm{m}$, where microcrack can be noticed.

Higher release of energy allows microcracks to emerge. The change in contrast and brightness is noticed when relative humidity drops to $40 \%$, which is probably related to changes in free energy. This implies that changes of surface energy (Gibbs-Bangham shrinkage) should be related to changes in fracture energy, since during drying, some energy is liberated. According to Griffith [25], crack growth occurs when the energy required for crack growth is present i.e. somehow delivered by the system itself. In the case of drying shrinkage, there are no external mechanical loads during early drying process so the required energy must initiate from 'inside'. It is delivered as a release of elastic energy [25, 26]. That is why drying deformations are more or less always accompanied by some microcracking (Figs. 7, 8). It was not possible to find out the influence of microcracking on the speed of drying in these tests, since generally speaking, microcracking could speed up the loss of water and moisture flow with a consequential shrinkage [27]. This indicates the mutual connections between shrinking and cracking but also brings out the 'chicken-and-egg' situation - which comes first, shrinkage or cracking?

\section{COEFFICIENT OF DEFORMATIONS}

The shrinkage coefficient $\alpha_{\mathrm{sh}}$ defines the shrinkage strain per unit change of relative humidity assuming that the there are no constrains for sample movement. The term 'shrinkage coefficient' should be probably replaced with 'coefficient of deformations', since both shrinkage and expansion occur during drying. In order to compute the coefficient of deformations for the dried samples, the light fixation of the thin samples to the cooling stage with the convection paste was assumed a negligible constraint. 
The statistical analysis is used to compute the coefficient in a straightforward manner. A method of regression is applied based on the strain results from the Vic-2D correlation analysis. Regression shows the strength of the relation between two phenomena. In this case, it is the influence of relative humidity to the drying deformations. The method used is based on the least square method of line fitting. The hypothesis about the direct proportionality of (shrinkage) strain to RH (similar to equations in L'Hermite [2] and Bangham and Fakhoury [28]), is made in the whole drying range (100\%$20 \% \mathrm{RH})$. Consequently, the ESEM test-setup directly relates the change of deformations to the change in relative humidity. To avoid a polynomial approximation of $4^{\text {th }}$ or $5^{\text {th }}$ order, a simplified linear regression analysis is applied on the drying curves $(\varepsilon-\mathrm{RH})$ in Fig. 5. Calculations are performed in the Matlab code with the following algorithms:

$$
Y_{c}=a+b X
$$

where $a$ and $b$ are regression coefficients, calculated from a bivariate distribution of the strain $Y_{c}$, predicted from a value $X$ (variable relative humidity). Equation 2 can be rewritten as equation 3:

$$
\varepsilon_{c}=a+b(\Delta h)
$$

Since it is necessary to calculate both the correlation coefficient and the regression coefficients, the so-called blanched formula for $r$ (correlation coefficient) is applied:

$$
r=\frac{\frac{\sum X Y}{N}-(\bar{X} \bar{Y})}{\left(S_{X}\right)\left(S_{Y}\right)}
$$

where $\bar{X}$ and $\bar{Y}$ are mean values of variables $X$ and $Y ; N$ is a number of pairs of observations, $S$ is a standard deviation for $X$ and $Y$. Standard deviation (for example for $S_{x}$ ) can be calculated from (Eq. 5):

$$
S_{X}=\sqrt{\frac{\sum X^{2}-\frac{\left(\sum X\right)^{2}}{N}}{N}}
$$

The regression coefficient $b$, can be calculated from (Eq. 6):

$$
b=r \frac{S_{X}}{S_{Y}}
$$

where $r$ is a correlation coefficient for $X$ and $Y, S_{x}$ and $S_{y}$ are standard deviations of variable $X$ and $Y$. The value for $b$ can be expressed as follows:

$$
b=\frac{\sum X Y-N \bar{X} \bar{Y}}{\sum X^{2}-N \bar{X}^{2}}
$$

Coefficient $a$ can be computed from (Eq. 8):

$$
a=\bar{Y}-b \bar{X}
$$

In this particular calculation, the variable $X$ presents the values of relative humidity in the range from $100 \%$ to $20 \% \mathrm{RH}$, and the $Y$ values are deformations in the three directions ( $\mathrm{x}-\mathrm{x}, \mathrm{y}-\mathrm{y}$ and $\mathrm{x}-\mathrm{y}$ ). The value $b$ is taken as a constant (shrinkage) deformation coefficient. It presents the slope of the regression line, where sign $(+)$ shows tendency of shrinkage and sign (-) tendency of expansion.

In principle, the shrinkage/expansion coefficient can be computed for the three RH intervals: $100 \%-70 \%$ RH, $70 \%-40 \%$ RH and below 40\% RH (till 20\% RH). Different shrinkage mechanisms are active at each RH interval. Thus, the coefficient is calculated as 'global' for the full drying (100\%-20\% RH) and 'local' in the above mentioned RH ranges. The global and local coefficients for samples in (Fig. 5) are presented in Table 1 and 2 respectively. 
Table 1. Global shrinkage coefficients for neat cement paste samples for drying range $100 \%-20 \% \mathrm{RH}$.

\begin{tabular}{|c|c|c|c|c|c|}
\hline \multirow{3}{*}{$\begin{array}{c}\text { CURING } \\
\text { (days) } \\
\text { Wet }\end{array}$} & \multirow{2}{*}{\multicolumn{2}{|c|}{$\begin{array}{c}\text { MATERIAL } \\
\text { CHARACTER. }\end{array}$}} & \multicolumn{3}{|c|}{ SHRINKAGE COEFFICIENT } \\
\hline & & & \multirow{2}{*}{$\frac{b_{x x}}{\text { all } R H}$} & \multirow{2}{*}{$\frac{b_{y y}}{\text { all } R H}$} & \multirow{2}{*}{$\frac{b_{x y}}{\text { all } R H}$} \\
\hline & CEM type & $w / c$ & & & \\
\hline 4 & I 32.5R & 0.5 & $-9.8 E-05$ & -0.00012 & $-1.81 E-06$ \\
\hline 5 & I 32.5R & 0.5 & $6.04 E-05$ & 1.77E-05 & $-4.44 E-05$ \\
\hline 32 & I 32.5R & 0.5 & -0.00019 & 0.00015 & 4.07E-05 \\
\hline 52 & I 32.5R & 0.5 & 0.00017 & -0.00019 & $6.49 E-05$ \\
\hline
\end{tabular}

Table 2. Local shrinkage coefficients for neat cement paste samples for the three drying ranges: $100 \%-70 \% \mathrm{RH}, 70 \%-40 \%$ $\mathrm{RH}$ and $\mathrm{RH}<40 \%$.

\begin{tabular}{|c|c|c|c|c|c|c|c|c|c|c|c|}
\hline \multirow{3}{*}{\begin{tabular}{|c|}
$\begin{array}{c}\text { CURING } \\
\text { (days) }\end{array}$ \\
Wet
\end{tabular}} & \multirow{2}{*}{\multicolumn{2}{|c|}{$\begin{array}{c}\text { MATERIAL } \\
\text { CHARACTER. }\end{array}$}} & \multicolumn{9}{|c|}{ SHRINKAGE COEFFICIENT (neat cement paste) } \\
\hline & & & \multicolumn{3}{|c|}{$b_{x x}$} & \multicolumn{3}{|c|}{$b_{y y}$} & \multicolumn{3}{|c|}{$\mathbf{b}_{\mathrm{xy}}$} \\
\hline & CEM type & w/c & $\mathrm{RH}<40 \%$ & $40 \%-70 \%$ & $70 \%-100 \%$ & $\mathrm{RH}<40 \%$ & $40 \%-70 \%$ & $70 \%-100 \%$ & $\mathrm{RH}<40 \%$ & $40 \%-70 \%$ & $70 \%-100 \%$ \\
\hline 4 & I 32.5R & 0.5 & $-6.5 \mathrm{E}-05$ & -0.0002 & $-6.55 \mathrm{E}-05$ & -0.0002 & -0.0002 & $-3.11 E-05$ & $-6 E-06$ & $-3 E-06$ & 1.63E-05 \\
\hline 5 & I 32.5R & 0.5 & 8.09E-05 & $6.5 E-05$ & $-3.38 \mathrm{E}-06$ & $-5 E-06$ & 2.9E-05 & $-1.1 E-06$ & 1.1E-05 & $-8 E-05$ & 1.31E-06 \\
\hline 32 & I 32.5R & 0.5 & -0.00174 & $-8 \mathrm{E}-05$ & $-8.11 E-06$ & 0.00123 & 4.8E-05 & $3.29 \mathrm{E}-06$ & 0.0006 & $-4 E-05$ & 2.26E-06 \\
\hline 52 & | 32.5R & 0.5 & 0.00101 & 0.00011 & $3.78 \mathrm{E}-07$ & -0.0014 & $-2 E-06$ & $-2.88 E-06$ & 0.00055 & 1.3E-05 & 1.82E-06 \\
\hline
\end{tabular}

The following is observed. Although generally speaking, shrinkage/expansion during drying from $100 \%$ to $30 \% \mathrm{RH}$ reduces with aging, the global coefficient increases in $\mathrm{x}-\mathrm{x}$ and $\mathrm{y}$-y direction for mature samples (Table 1). The reasons are the very high deformations at $20 \% \mathrm{RH}$, which occur in 32- and 52-day samples.

When the RH range is split into three groups (Table 2), it can be observed that the coefficient variations are additionally influenced by the relative humidity, especially in the three $\mathrm{RH}$ groups: below $40 \% \mathrm{RH}$, as expected and in $40 \%-70 \% \mathrm{RH}$ and $70 \%-100 \% \mathrm{RH}$, unexpectedly.

This could be a combined result of capillary stress and disjoining pressure, which are the active deformation mechanisms in that range. The coefficient is the lowest during drying between $100 \%$ and $70 \% \mathrm{RH}$ (order of magnitude $1 \times 10^{-5}$ in $4-$ day sample to $1 \times 10^{-7}$ in 52-day sample). That is the RH at which the highest amount of water leaves but the lowest deformations occur. The coefficient increases from $70 \%$ to $40 \%$ RH in 4-day sample and 52-day sample to about $1 \times 10^{-4}$. The highest shrinkage coefficient appears below $40 \% \mathrm{RH}\left(1 \times 10^{-3}\right)$ in more mature samples due to high deformations, as already mentioned. In the presented tests, aging increases shrinkage coefficient at low $\mathrm{RH}(<40 \%)$ due to microcracking that occurred. Shrinkage and microcracking at low RH $(<40 \%)$ are attributed to changes in surface free energy (GibbsBangham shrinkage). Thus, the shrinkage/expansion assumptions about the behaviour of microstructure during drying, previously given, are also applicable here.

\section{CONCLUSIONS}

The novel method of sample preparation enables the handling and testing of cement paste at a very young age (already at 2 days of age) and different curing conditions. Improved ESEM techniques in combination with digital image analysis enable observation and determination of strains in $1 \mathrm{~mm}$ thick sample at micro-scale in a nondestructive way. The new techniques offer new findings about early age behaviour of cement-based microstructure when exposed to drying conditions. The behaviour of microstructure is very complex when exposed to environmental changes. Actually, the lower the length scale, the more complex the observations. It also seems that the cement paste matrix behaves more like a 'living tissue' and less like a non-living material [23].

The expected isotropic drying shrinkage behaviour observed at the macro-scale is actually a highly orthotropic and nonlinear at the micro-scale. This is attributed to non-uniform moisture flow and drying of heterogeneous cement paste microstructure and particularly two-phased C-S-H. Roughly speaking, the three drying intervals in the average strain- $\mathrm{RH}$ 
diagrams can be distinguished at 100\%-70\% RH, 70\%-40\% RH and below 40\% RH. Depending on the RH interval and sample characteristics (age, w/c ratio, curing conditions), cement paste reacts differently. In cement paste up to 4 days of age, only expansion is present. Over 4 days samples undergo both expansion and shrinkage. Expansion and shrinkage occur regardless of the sample age, which was also confirmed by Neubauer [11]. The domination of expansion or shrinkage depends on the sample age such that expansion in early-age samples is mostly 'replaced' by shrinkage in mature samples. This applies especially for strain components $\varepsilon_{\mathrm{xx}}$ and $\varepsilon_{\mathrm{yy}}$.

With aging, deformation (expansion or shrinkage) decreases in mature samples but only from $100 \%$ to $30 \%-40 \%$ RH. Below $40 \% \mathrm{RH}$, the Gibbs-Bangham shrinkage dominates, which is characterized by a reduction of surface energy and liberation of a certain amount of energy. The liberated energy enables development of microcracks. Consequently, at $20 \% \mathrm{RH}$, equally high shrinkage and expansion occur due to the discontinuous microcracking.

Although cracking is considered to be an apparent shrinkage mechanism, which should be avoided by drying of thin specimens and thus determining only real shrinkage, it seems that shrinkage and cracking are interrelated. According to drying test results presented, the $1 \mathrm{~mm}$ thick samples still contain a moisture gradient (note that temperature on the top and the bottom of the examined samples differ during drying up to one degree). According to these tests, microcracking is still to some extent influenced by the aging but probably even more by the size of the drying step. Maybe a very small drying step $(5 \% \mathrm{RH})$ would be the most suitable for real shrinkage studies on a thin $(1 \mathrm{~mm})$ sample which would contribute to avoid microcracking completely. It is also possible that microcracking in cementitious materials cannot be avoided but only controlled.

On the other hand, the reduction of the drying step (from $20 \% \mathrm{RH}$ to $10 \% \mathrm{RH}$ ) determines the higher oscillations in the deformations which could be attributed to the applied testing techniques. Still, it is remarkable that oscillations have repeated in the same intervals in all samples.

The coefficient of deformation (shrinkage/expansion) is directly related to shrinkage/expansion and depends on the same factors. The local coefficients computed at partial RH ranges (Table 2) show dependence of the variable RH. It is practically impossible to establish one value for shrinkage/expansion coefficient since the coefficient changes with sample age, variations of RH and the direction (x-x,y-y and $x-y)$. The magnitude coefficient is usually around $1 \times 10^{-5}$ till $40 \%$ RH. Below $40 \%$ RH it may reach order of magnitude $1 \times 10^{-3}$.

The shrinkage results agree in principle in the drying trend with the tests on cement paste given in the literature, while showing that size effect in these ESEM tests, probably does not play the key role [3-6]. Regardless of the specimen size and an existing size effect, the order of magnitude of shrinkage strains in these tests was $1 \times 10^{-3}$. This applies for larger and smaller cement paste, mortar, or concrete specimens dried to $20 \% \mathrm{RH}$, with characteristics of w/c $\sim 0.5$ and 28 days old. It is arguable if the obtained shrinkage/expansion deformations at micro-scale should be fully comparable to the deformations at macro-scale.

Although nondestructive drying testing with ESEM gives a lot of valuable data regarding drying response of cement paste, the experimental results leave us with many questions. Further technical improvement of ESEM, detailed chemical and pore analysis of cement paste samples during drying as well as further data could help to learn more about the bahaviour of cement-based microstructures during drying.

\section{ACKNOWLEDGEMENTS}

I would like to gratefully acknowledge: the technical assistance of Mr. Kees van Beek and Mr. Paul Vermeulen, with the cooling stage, and Mr. Rinus Maasakkers for ESEM maintenance; STW and TU Delft for funding my Ph.D. research and the Delft Microlab for use of its ESEM and laboratory. Special thanks to Dr. Ed Garboczi for the article review and constructive suggestions.

I would like to dedicate this article to my late cousin Nebojsa, who always encouraged me in my research work.

\section{REFERENCES}

[1] Martinola, G. and Wittmann, F.H., "Application of fracture mechanics to optimize repair mortar systems", Proc. Fracture Mechanics of Concrete Structures FRAMCOS-2, ed. Wittmann, F.H., Aedificatio Publishers, D-79104 Freiburg, 1481-1492 (1995). 
[2] L'Hermite, R.G., "Volume changes of concrete", Proc. $4^{\text {th }}$ Int. Sym. on the Chemistry of Cement, V-3. NBS Monograph 43, NBS, Washington, D.C., 659-694 (1960).

[3] Pihlajavaara, S.E., [On the main features and methods of investigation of drying and related phenomena in concrete], Ph.D. Thesis, University of Helsinki, Julkaisu 100 Publication, The State Institute for Technical Research, Finland, (1965).

[4] Hansen, W., "Drying shrinkage mechanisms in Portland cement pastes", Journal of American Ceramic Society 70(5), 323-328 (1987).

[5] Ferraris, C.F. and Wittmann, F.H., "Shrinkage mechanisms of hardened cement paste", Cement and Concrete Research 17, 453-464 (1987).

[6] Alvaredo, A.M., "Crack formation under hygral or thermal gradients", Fracture Mechanics of Concrete Structures, ed. Wittmann, F.H. Aedificio, Freiburg, Germany, 1423-1441 (1995).

[7] Helmuth, R.A. and Turk, D.H., "The reversible and irreversible drying shrinkage of hardened Portland cement and tricalcium silicate pastes", Journal of the PCA Research and Development Laboratories 9(2), 8-21 (1967).

[8] Wittmann, F.H., "Creep and shrinkage mechanisms”, Creep and Shrinkage in Concrete Structures, eds. Bažant, Z.P. and Wittmann, F.H., John Wiley and Sons, New York, 129-161 (1982).

[9] Sujata, K., Xi, Y. and Jennings, H.M., "Interfacial shrinkage in mortars", Materials for the New Millennium, Proc. $4^{\text {th }}$ Engineering Division of the American Society of Civil Engineers, ed. Chong, K.P., F.ASCE (2) A 469, Washington, D.C., (1996).

[10] Neubauer, C.M., Jennings, H.M. and Garboczi, E.J., "Mapping drying shrinkage deformations in cement-based materials", Cement and Concrete Research 27(10), 1603-1612 (1997).

[11] Neubauer, C.M., [On the chemistry, microstructure, and deformation properties of cement pastes: towards a new strategy for controlling drying shrinkage], Ph.D. Thesis, Northwestern University, Illinois, USA, (1997).

[12] Danilatos, G.D., "Design and construction of an atmospheric or environmental SEM (Part 1)", Scanning 7, 26-42 (1985).

[13] Jankovic, D. and Van Mier, J.G.M., "Crack development in concrete due to moisture flow", HERON 46, ISSN 0046-7316, 169-180 (2002).

[14] Jankovic, D., "Study of 'real' shrinkage by ESEM observations and digital image analysis", Proc. 3 rd Int. Conf. on Structural Engineering Mechanics and Computation, Cape Town, South Africa, September 10-12, ed. A. Zingoni, (long paper on CD), Millpress Science Publishers, Rotterdam, 1500-1505 (2007).

[15] Chu, T.C., Ranson, W.F., Sutton, M.A. and Peters, W.H., "Application of digital image correlation technique to experimental mechanics", Experimental Mechanics 25, 232-244 (1985).

[16] Sutton, M.A., Wolters, W.J., Peters, W.H., Ranson, W.F., and McNeill, S.R., "Determination of displacements using an improved digital correlation method", Image and Vision Computing 1(3), 133-139 (1983).

[17] Bruck, H.A., McNeill, S.R., Sutton, M.A., and Peters, W.H. III, "Digital image correlation using Newton-Raphson method of partial differential correlation", Experimental Mechanics 28(3), 261-267 (1989).

[18] Neubauer, C.M. and Jennings H.M., "The use of digital images to determine deformation throughout a microstructure, Part II, Application to cement paste”, Journal of Materials Science 35, 5751-5765 (2000).

[19] Roper, H., "Dimensional change and water sorption studies of cement paste", Hwy. Res. Bd. Spec. Report 90, 74-83 (1966).

[20] Jennings, H.M., Garci, M., Neubauer, C.M., Moss, G.M., Tennis, P.D. and O’Neil, E.F., "Why volume changes matter: relationship between microstructure and shrinkage", Concrete International, 50-53 (2000).

[21] Gibbs, J.W., [Collected works], New Haven, (Conn.) Yale University Press, (1943).

[22] Mindess, S., Young, J.F. and Darwin, D., [Concrete], Prentice Hall, Pearson Education, Inc., 2nd Ed., (2003).

[23] Freyssinet, E., "The deformation of concrete", Magazine of Concrete Research 3(8), 49-56 (1951).

[24] Wittmann, F.H., "Deformation of concrete at variable moisture content", Mechanics of Geomaterials, ed. Bazant, Z.P., Wiley, New York, $425-459$ (1985).

[25] Griffith, A.A., "The phenomena of rupture and flow in solids”, Phil. Trans. R. Soc. London A 221, 163-198 (1921).

[26] Broek, D., [Elementary engineering fracture mechanics], Martinus Nijhoff Publishers, (1986).

[27] Neville, A.M., [Properties of concrete], John Wiley and Sons, Inc., $4^{\text {th }}$ edition, E. Longman, (1995).

[28] Bangham, D.H. and Fakhoury, N., "The translational motion of molecules in the adsorbed phase on solids", J. Chem. Soc., 1324-1333 (1931). 